\title{
The influence of shelterbelts in arable farmland on beneficial and pest invertebrates
}

\author{
M.M. Davidson ${ }^{1}$, B.G. Howlett ${ }^{1}$, R.C. Butler ${ }^{1}$, N.M. Taylor ${ }^{2}$ and M.K. Walker ${ }^{1}$ \\ ${ }^{1}$ The New Zealand Institute for Plant E Food Research Limited, Private Bag 4704, \\ Christchurch Mail Centre, Christchurch 8140, New Zealand \\ ${ }^{2}$ The New Zealand Institute for Plant E Food Research Limited, Hawke's Bay \\ Research Centre, Private Bag 1401, Havelock North, New Zealand \\ Corresponding author:melanie.davidson@plantandfood.co.nz
}

\begin{abstract}
Shelterbelts of Pinus radiata and Cupressus macrocarpa are common landscape features on arable farmland in New Zealand. This study aimed to determine whether such shelterbelts could influence the relative abundance and diversity of beneficial and pest invertebrates commonly found in arable crops. Window intercept, yellow sticky and pitfall traps were placed next to shelterbelts or post and wire fences and also $50 \mathrm{~m}$ from these borders into adjacent crops on two arable farms in Canterbury and one in Wairarapa over 1-2 weeks in summer 2012 and autumn 2013. The abundance of given species/taxa varied considerably depending on farm location, season and field border type. However, the mean number of beneficial insect species/taxa per trap did not vary markedly between field border types or adjacent crops, while traps at shelterbelts or their adjacent crops caught more of some pest species/taxa than traps beside fences. The pine/macrocarpa shelterbelts did not markedly increase relative abundance or diversity of beneficial insects.
\end{abstract}

Keywords arable, cropping, insect pollinators, predators, parasitoids, pests, diversity, abundance, trapping.

\section{INTRODUCTION}

Shelterbelts of pine (Pinus radiata) and/or macrocarpa (Cupressus macrocarpa) are common landscape features on arable farmland in New Zealand. Price (1993) estimated such shelterbelts extended to nearly $100,000 \mathrm{~km}$ on the Canterbury Plains. They were established predominantly for protection against wind (Price 1993), although they also provide a habitat for invertebrate and vertebrate species (Bowie et al. 2014; Lemmers et al. 2014). Arable crops include a variety of seed crops (e.g. clover, radish, peas, carrot), cereals and maize, and legumes. Seed crops often rely on insect pollinators and a range of insect species can provide a similar level of pollination to honey bees (Apis mellifera L.) (Rader et al. 2012), and when present alongside honey bees, they can boost yields (Garibaldi et al. 2013). Natural enemies can be an important component of integrated management strategies for regulating arable pest populations (Horrocks et al. 2010). Additionally, some insects can play a dual role as both pollinators and predators (e.g. hoverflies). A previous study has shown differences in the number of spiders and beetles at fence lines and macrocarpa shelterbelts, with some species more abundant in pitfall traps in or near the shelterbelts 
(Bowie et al. 2014). Similarly, more calliphorids (Calliphora stygia (Fabricius), C. vicina RobineauDesvoidy, Lucilia sericata (Meigen)), Tachinidae and the syrphid Melangyna novaezelandiae (Macquart) were present in window intercept traps along pine/macrocarpa shelterbelts than in traps beside post and wire fence lines, when both were bordering pasture fields (Walker et al. 2008). Honeybees were less abundant in traps beside pine/macrocarpa shelterbelts, whereas a similar number of Melanostoma fasciatum, Dilophus nigrostigma (Walker), Bombus spp., Muscidae and Dolichopodidae were caught in traps along fence lines or pine/macrocarpa shelterbelts (Walker et al. 2008). Given the prevalence of pine/ macrocarpa shelterbelts in arable farming systems this study aimed to determine whether they might unintentionally influence the relative abundance and diversity of beneficial and pest invertebrates commonly found in neighbouring arable crops.

\section{MATERIALS AND METHODS}

Window intercept traps, yellow sticky traps and pitfall traps were set up on three arable farms [coastal Canterbury (41 0423 S, 1720619 E, 21 m above sea level (a.s.l.)), inland Canterbury (43 32 $01 \mathrm{~S}, 1720359 \mathrm{E}, 172 \mathrm{~m}$ a.s.l.) and Wairarapa (41 $0423 \mathrm{~S}, 1753534 \mathrm{E}, 39 \mathrm{~m}$ a.s.l.)] to monitor selected beneficial and pest invertebrate species or groups. At each farm, two of each trap type were set up along two replicates ( $n=4$ per trap type) of post and wire fence lines or pine/macrocarpa shelterbelts (10-20 $\mathrm{m}$ tall) approximately $40 \mathrm{~m}$ apart. At the same time, two of each trap type were set up within an adjacent crop (two replicate sites, $\mathrm{n}=4$ per trap type) approximately $50 \mathrm{~m}$ from the traps at the field borders. Adjacent crops were corn salad seed, spinach seed, maize, oats, barley, ryegrass seed, linseed, lucerne or ryegrass pasture. Sampling periods were in early summer (Canterbury 10-17 Dec. 2012 and Wairarapa 4-11 Dec. 2012), and early autumn (Canterbury 13-27 Mar. 2013 and Wairarapa 10-17 Apr. 2013). On the Canterbury farms three additional pitfall traps were set up between the two window and sticky traps along the field margins in December. In the autumn sampling at the coastal Canterbury farm, traps along one of the fence lines could not be set up because of grazing stock, and on the inland Canterbury farm one of the pitfall traps was missing in summer, and no traps could be set up in adjacent crops at this farm in autumn because of grazing stock.

Window traps were yellow 6-litre plastic trays with two Perspex windows $(36.4 \times 27 \mathrm{~cm}$ and $23.8 \times 27 \mathrm{~cm})$ perpendicular to one another, intersecting at the midway point sitting inside the tray, three-quarters filled with water and a few drops of detergent (Howlett et al. 2009). Window traps were placed on inverted 10-litre green buckets, $25 \mathrm{~cm}$ above the ground. Similar traps have successfully been used to look at insect pollinator distributions around hedgerows and other on-farm features (Walker et al. 2008). At $0.5 \mathrm{~m}$ from the window trap, a $10 \times 25 \mathrm{~cm}$ yellow sticky trap (Horriver TR, Koppert, the Netherlands) was set up between two $1.2 \mathrm{~m}$ poles with fold back clips, so the base of the trap was $1 \mathrm{~m}$ above the ground. Approximately $0.5 \mathrm{~m}$ from the window trap on the opposite side to the sticky trap, a pitfall trap (350 $\mathrm{ml}$ pot), was dug into the ground, ensuring the top of the pot was flush with the ground. Approximately $50 \mathrm{ml}$ of undiluted automotive antifreeze was poured into the pitfall trap. At the end of the sampling periods the contents of the window or pitfall traps were transferred to containers with $75 \%$ ethanol in the field (window traps) or in the laboratory (pitfall traps). Numbers of individuals of species or groups of insects were recorded for pollinating insects (bees, flies), natural enemies, pests and a mix of undifferentiated groups (putative herbivores, pests, detritivores). Pollinating bees included Apis mellifera L. (honey bee), Bombus terrestris L., B. ruderatus (Fab.) or B. hortorum (L.), Lasioglossum sordidum, Leioproctus sp., Leioproctus fulvescens (Smith). Pollinating flies included Calliphora stygia (Australian brown blow fly), Calliphora vicina (European blue blow fly), Lucilia sericata (European green blow fly), Calliphora quadrimaculata (Swedarius) (New Zealand blue blow fly), Pollenia pseudorudis Rognes (cluster fly), Hydrotaea rostrata RobineauDesvoidy (blue muscid), Delia platura (Meigen) 
(seedcorn fly), and Anthomyia punctipennis (Weideman) (three spotted fly). Natural enemies included parasitic Hymenoptera, Micromus tasmaniae (Walker) (brown lacewing), Forficula auricularia L. (common or European earwig), Carabidae (ground beetles), Staphylinidae (rove beetles), Coccinellidae (ladybirds), Araneae (spiders) and Phalangiidae (harvestmen). Pests included Limacidae (slugs), Costelytra zealandica (White) (grass grub), Elateridae (wireworms), Nysius huttoni White (wheat bug) and Mayetiola destructor (Say) (Hessian fly). The mix of undifferentiated groups included Curculionoidea (weevils), other Coleoptera, other Hymenoptera, Diptera, Heteroptera and Homoptera.

Data were summarised using summary statistics and graphically. In addition, three richness and diversity statistics were calculated for each trap: total numbers of individuals (regardless of species), number of species/groups and Simpson's Reciprocal Index (1/D). Total numbers and number of species were corrected to per trap per week, by dividing by the number of weeks that the trap was left out. Simpson's $1 / \mathrm{D}$ was calculated for each trap from $\mathrm{D}$, with $\mathrm{D}$ calculated as:

$$
D=\sum_{i} N_{i}\left(N_{i}-1\right) /(T(T-1))
$$

Here, $\mathrm{N}_{i}$ is the number of species $i$ on the trap, and $T$ is the total insects caught on the trap (not adjusted for trapping weeks in either case). Data for insects not present on the trap $\left(\mathrm{N}_{i}=0\right)$ were excluded from the calculation. There were two cases where the calculation resulted in $\mathrm{D}$ equal to 0 ; hence, $1 / \mathrm{D}$ for these two traps is undefined. An index value of 1 represents a community containing only one species, thus the higher the index the greater the diversity (i.e. a greater number of species of more even abundance between species has a higher 1/D value than a community with a few species of similar abundance or where one species has high abundance over other species present).

\section{RESULTS}

Window traps caught the highest mean number of bee and fly pollinators and pests, when all species and groups were combined (Table 1). Very few bees were caught on sticky traps or in pitfall traps, whilst very few pollinating flies were caught in pitfall traps. Some of the pests of interest were also caught in pitfall traps, but not on sticky traps. Window and sticky traps caught a similar number of natural enemies, three times higher than the number caught in pitfall traps (Table 1).

On average, more pollinating bees were caught in traps along the fence line ( 88 per trap per week) than in traps along shelterbelts (31 per trap per week) (Table 2). More than double the number of pollinating bees were caught on average in traps $50 \mathrm{~m}$ into crops adjacent to shelterbelts (94 per trap per week) than in traps $50 \mathrm{~m}$ into crops adjacent to fence lines (45 per trap per week). More pollinating flies were caught on sticky traps or in window traps along the fence line than along the shelterbelt, although a similar mean number were caught in crops adjacent to both types of border (Table 2). A similar mean number of natural enemies were caught along fence lines or shelterbelts for a given trap type. Likewise, similar numbers were caught for a given trap type in crops adjacent to either border

Table 1 The mean (minimum - maximum) number of insect pollinators (bees, flies), natural enemies and pests caught in the different trap types per week. Values are the means across all three farms and the two sample periods, summer (Dec. 2012) and autumn (Mar. or Apr. 2013).

\begin{tabular}{lrcccc}
\hline Trap type & $\begin{array}{r}\text { No. } \\
\text { traps }\end{array}$ & \multicolumn{1}{c}{ Bees } & \multicolumn{1}{c}{ Flies } & Enemies & Pests \\
\hline Pitfall & 100 & $1.5(0.0-138.0)$ & $0.7(0.0-5.0)$ & $10.5(0.0-63.0)$ & $3.4(0.0-60.0)$ \\
Sticky & 82 & $0.1(0.0-2.0)$ & $9.9(0.0-38.0)$ & $30.6(0.0-162.0)$ & $0.2(0.0-5.5)$ \\
Window & 82 & $64.6(0.0-370.0)$ & $28.1(0.0-154.0)$ & $30.4(0.0-371.0)$ & $21.6(0.0-501.5)$ \\
Overall & 264 & $20.7(0.0-370.0)$ & $12.1(0.0-154.0)$ & $22.9(0.0-371.0)$ & $8.0(0.0-501.5)$ \\
\hline
\end{tabular}


type, except more were caught in window traps at the border (shelterbelt traps 44 per trap per week, fence line 37 per trap per week) than in the adjacent crops (shelterbelt traps 17 per trap per week, fence line 19 per trap per week) (Table 2).

More pests were caught in window traps along shelterbelts (29 per trap per week) and their adjacent crops (59 per trap per week) than in window traps at fence lines (8 per trap per week) or in their adjacent crops (1 per trap per week) (Table 2). The pest species that were most commonly recorded, wheat bug and grass grub, were more abundant along the shelterbelts and/ or the adjacent crop compared to fence line traps (Table 3).

The closer the inverse Simpson's indices $(1 / D)$ are to zero, the fewer the species and less evenly spread (i.e. one or a few species dominate). The indices were similar (3.554.68) for border type (fence line, pine/ macrocarpa shelterbelt), trap location (at the border or into an adjacent crop), farm location,

Table 2 The mean (minimum - maximum) number of insect pollinators (bees, flies), natural enemies and pests caught in the different trap types per week at the different field margins (post and wire fence line, pine/macrocarpa shelterbelt) and in adjacent crops. Values are the means across all three farms and the two sample periods (summer (Dec. 2012) and autumn (Mar. or Apr. 2013)). Total number of window and sticky traps: at the borders $=46$, in adjacent crops $=36$. Total number of pitfall traps at the borders $=66$, in adjacent crops $=34$.

\begin{tabular}{lllcr}
\hline Insect group & Trap type & Trap location & Fence line & Shelterbelt \\
\hline Bees & Window & Border & $88.1(2-370)$ & $30.9(1-78)$ \\
& & Adjacent crop & $45.1(0-207)$ & $94.1(0-326)$ \\
Flies & \multirow{2}{*}{ Sticky } & Border & $16.0(0-37)$ & $7.1(0-23)$ \\
& & Adjacent crop & $6.6(0-22)$ & $8.3(0-38)$ \\
& \multirow{2}{*}{ Window } & Border & $41.0(4-154)$ & $20.6(0-75)$ \\
& & Adjacent crop & $26.0(1-58)$ & $22.2(1-64)$ \\
\multirow{2}{*}{ Natural enemies } & Pitfall & Border & $11.1(0.5-63)$ & $6.3(0-22)$ \\
& & Adjacent crop & $13.0(0-41)$ & $13.9(2-38)$ \\
& \multirow{2}{*}{ Sticky } & Border & $27.3(3.5-106)$ & $27.3(2-92)$ \\
& \multirow{2}{*}{ Window } & Adjacent crop & $39.1(0-162)$ & $30.4(2-145)$ \\
& & Border & $36.6(0-128)$ & $43.6(0-371)$ \\
& \multirow{2}{*}{ Pitfall } & Adjacent crop & $19.3(1-65)$ & $16.8(1-50)$ \\
& & Border & $2.8(0-11)$ & $2.1(0-24)$ \\
& \multirow{2}{*}{ Window } & Adjacent crop & $3.1(0-23)$ & $7.3(0-60)$ \\
& & Border & $8.5(0-81)$ & $29.2(0-466)$ \\
& & Adjacent crop & $1.2(0-4)$ & $50.1(0-501.5)$ \\
\hline
\end{tabular}

Table 3 The mean (minimum - maximum) number of the most abundant pest species (wheat bug and grass grub) caught in the different trap types per week at the different field margins (post and wire fence line, pine/macrocarpa shelterbelt) and in adjacent crops. Values are the means across all three farms and the two sample periods (summer (Dec. 2012) and autumn (Mar. or Apr. 2013)).

\begin{tabular}{lllcc}
\hline Pest & Trap type & Trap location & Fence line & Shelterbelt \\
\hline Wheat bug & Pitfall & Border & $1.1(0-11)$ & $2.3(0-26)$ \\
& & Adjacent crop & $4.1(0-46)$ & $0.2(0-3)$ \\
& Window & Border & $15.9(0-162)$ & $57.1(0-932)$ \\
& & Adjacent crop & $0.7(0-6)$ & $98.5(0-1003)$ \\
Grass grub & Pitfall & Border & $0.9(0-8)$ & $1.2(0-22)$ \\
& & Adjacent crop & $0.7(0-3)$ & $3.8(0-60)$ \\
& Window & Border & $0.3(0-2)$ & $0.6(0-4)$ \\
& & Adjacent crop & $0.6(0-4)$ & $0.4(0-6)$ \\
\hline
\end{tabular}


sample periods and trap type. This indicates that the number of species and individuals of a given species was similar between the different factors listed in Table 4. However, total number of individuals and to a lesser extent, species/ taxa number, varied between these factors. More individuals were caught in traps along the fence line than in the shelterbelt, coastal Canterbury than inland Canterbury, in the autumn sample period than in summer, and in window traps than in pitfall or sticky traps. The main differences in number of species/taxa were recorded in different trap types, where window traps caught a greater range of species/groups than the other two trap types (Table 4).

\section{DISCUSSION}

Based on the methods used, no apparent differences were detected between trap capture of beneficial insects at shelterbelts and those at post and wire fence lines. In contrast, there were more pest species/taxa caught in traps along pine/ macrocarpa shelterbelts and/or traps $50 \mathrm{~m}$ into arable crops adjacent to the shelterbelts, than along post and wire fences or their adjacent crops. This would suggest that the traps and methods used can detect differences, should they exist, for the species/taxa that would be caught in these types of traps. A previous study had reported an increase in the capture of pollinating insect species in window traps along pine/macrocarpa shelterbelts compared with traps along post and wire fences bordering pasture (Walker et al. 2008). In the present study, this trend was observed in traps $50 \mathrm{~m}$ into crops adjacent to shelterbelts, but not in traps at the shelterbelt borders. This may have been due to the diversity of crops adjacent to the field borders sampled in the present study, including flowering seed crops pollinated by insects (e.g. corn salad, radish), or the type of farm where the study was conducted; the present study was conducted on arable farms as opposed to the dairy farms used by Walker et al. (2008). Shelterbelts may also be inhibiting the movement of flying insects; for example, hoverfly movement has been shown to be inhibited by poplar (Populus nigra L. var. italica du Roi) barriers at field margins (Wratten et al. 2003) and therefore have the potential to influence abundances near these features. A previous study has reported increased numbers of some species of spiders and predatory Carabidae and Staphylinidae (Bowie et al. 2014), but it is uncertain how these species may contribute to pest suppression in adjacent arable crops. None of the Carabidae species reported in Bowie et al. (2014) were found in arable crops surveyed as part of an integrated pest management monitoring programme

Table 4 The mean (minimum - maximum) number of individuals caught per trap per week for total number of individuals, number (No.) of species or groups, and the Simpson's index at the different borders (post and wire fence lines, pine/macrocarpa shelterbelt), at the border or in an adjacent crop, at the three farms, for the different sample periods (summer (Dec. 2012) and autumn (Mar. or Apr. 2013)) and trap types.

\begin{tabular}{llccl}
\hline Factor & Description & Total individuals & No. Species & Simpson's 1/D \\
\hline Border type & Fence line & $100.8(1.0-1099.5)$ & $7.7(1.0-19.0)$ & $4.13(1.00-28.00)$ \\
& Shelterbelt & $77.2(2.0-710.5)$ & $7.2(1.5-19.0)$ & $4.25(1.33-28.00)$ \\
Trap location & Border & $90.0(1.0-1099.5)$ & $7.3(1.0-17.0)$ & $4.36(1.12-28.00)$ \\
& Adjacent crop & $88.7(1.0-787.0)$ & $7.8(1.0-19.0)$ & $3.94(1.00-28.00)$ \\
\multirow{2}{*}{ Farm } & Coastal Canterbury & $109.4(3.0-1099.5)$ & $7.1(2.0-19.0)$ & $4.44(1.31-28.00)$ \\
& Inland Canterbury & $59.0(2.0-823.0)$ & $6.7(1.0-17.0)$ & $4.52(1.00-11.21)$ \\
\multirow{3}{*}{ Sample periods } & Wairarapa & $92.7(1.0-474.0)$ & $8.5(1.0-17.0)$ & $3.68(1.20-28.00)$ \\
\multirow{3}{*}{ Trap type } & Summer 2012 & $59.1(3.0-181.0)$ & $8.6(1.0-19.0)$ & $4.39(1.00-28.00)$ \\
& Autumn 2013 & $124.3(1.0-1099.5)$ & $6.2(1.0-17.0)$ & $3.95(1.12-10.91)$ \\
& Pitfall & $24.8(1.0-146.0)$ & $5.1(1.0-11.0)$ & $4.63(1.12-28.00)$ \\
& Sticky & $55.3(5.0-181.0)$ & $6.6(1.0-11.0)$ & $3.55(1.00-8.21)$ \\
& Window & $202.5(10.0-1099.5)$ & $11.4(4.0-19.0)$ & $4.32(1.31-11.21)$ \\
\hline
\end{tabular}


(Horrocks et al. 2010). The potential to increase the abundance and diversity of beneficial insects by establishing perennial plants that provide the landscape features (food, shelter, etc.) they use, without creating barriers to movement, allowing reservoirs for pests, or resulting in increased pollination or pest predation in surrounding arable crops is the subject of a current Sustainable Farming Fund project (Howlett et al. 2013).

\section{ACKNOWLEDGEMENTS}

We wish to thank the farmers, John Evans, Paul Jarman and Michael Williams, for access to their properties. Thanks to Stacey Skill, Sam Read, Joep van Cranenbroek, Mathilde Dusart, Fanny LeBarbier and Pim Lemmers for their assistance with the sampling at the Canterbury farms. This work was in part funded by a Ministry for Primary Industries Sustainable Farming Fund project (12015, Building Better Biodiversity on Cropping Farms). The work was also supported by MBIE through Plant \& Food Research core funding.

\section{REFERENCES}

Bowie MH, Klimaszewski J, Vink CJ, Hodge S, Wratten SD 2014. Effect of boundary type and season on predatory arthropods associated with field margins on New Zealand farmland. New Zealand Journal of Zoology 41: 268-284. Garibaldi LA, Steffan-Dewenter I, Winfree R, Aizen MA, Bommarco R, Cunningham SA, Kremen C, Carvalheiro LG, Harder LD, Afik O, Bartomeus I, Benjamin F, Boreux V, Cariveau D, Chacoff NP, Dudenhoeffer JH, Freitas J, Ghazoul J, Greenleaf S, Hipolito J, Holzschuh A, Howlett B, Isaacs R, Javorek SK, Kennedy CM, Krewenka KM, Krishnan S, Mandelik Y, Mayfield MM, Motzke I, Munyuli T, Nault BA, Otieno M, Petersen J, Pisanty G, Potts SG, Rader R, Ricketts TH, Rundlof M, Seymour CL, Schueepp C, Szentgyoergyi H, Taki H, Tscharntke T, Vergara CH, Viana BF, Wanger TC, Westphal C, Williams N, Klein AM 2013. Wild pollinators enhance fruit set of crops regardless of honey bee abundance. Science 339: 1608-1611.
Horrocks A, Davidson MM, Teulon DAJ, Horne PA 2010. Demonstrating an integrated pest management strategy in autumn-sown wheat to arable farmers. New Zealand Plant Protection 63: 47-54.

Howlett BG, Walker MK, Newstrom-Lloyd LE, Donovan BJ, Teulon DAJ 2009. Window traps and direct observations record similar arthropod flower visitor assemblages in two mass flowering crops. Journal of Applied Entomology 133: 553-564.

Howlett BG, Davidson MM, Mathers D, Pyke NB 2013. Hedgerow plants to support crop pollination and pest management. The Weta 46: 3-12.

Lemmers P, Davidson MM, Butler RC 2014. Relative abundance of introduced European birds varies with field margin type on arable farms in Canterbury, New Zealand. New Zealand Journal of Zoology 41: 203-209.

Price LW 1993. Hedges and shelterbelts on the Canterbury plains, New Zealand: Transformation of an antipodean landscape. Annals of the Association of American Geographers 83: 119-140.

Rader R, Howlett BG, Cunningham SA, Westcott DA, Edwards W 2012. Spatial and temporal variation in pollinator effectiveness: Do unmanaged insects provide consistent pollination services to mass flowering crops? Journal of Applied Ecology 49: 126-134.

Walker MK, Howlett BG, Butler RC 2008. The effect of landscape features on pollinator distribution in a Canterbury agroecosystem. Plant \& Food Research Confidential Report No 2102 for the Foundation for Arable Research. Plant \& Food Research, Lincoln, New Zealand. 25 pp.

Wratten SD, Bowie MH, Hickman JM, Evans AM, Sedcole JR, Tylianakis JM 2003. Field boundaries as barriers to movement of hover flies (Diptera : Syrphidae) in cultivated land. Oecologia 134: 605-611. 